\title{
ORIGINAL ARTICLE Molecular basis underlying resistance to Mps1/TTK inhibitors
}

\author{
A Koch, A Maia, A Janssen ${ }^{1}$ and RH Medema
}

Mps1/TTK is a dual-specificity kinase, with an essential role in mitotic checkpoint signaling, which has emerged as a potential target in cancer therapy. Several Mps1/TTK small-molecule inhibitors have been described that exhibit promising activity in cell culture and xenograft models. Here, we investigated whether cancer cells can develop resistance to these drugs. To this end, we treated various cancer cell lines with sublethal concentrations of a potent Mps1/TTK inhibitor in order to isolate inhibitor-resistant monoclonal cell lines. We identified four point mutations in the catalytic domain of Mps1/TTK that gave rise to inhibitor resistance but retained wildtype catalytic activity. Interestingly, cross-resistance of the identified mutations to other Mps1/TTK inhibitors is limited. Our studies predict that Mps1/TTK inhibitor-resistant tumor cells can arise through the acquisition of mutations in the adenosine triphosphatebinding pocket of the kinase that prevent stable binding of the inhibitors. In addition, our results suggest that combinations of inhibitors could be used to prevent acquisition of drug resistance. Interestingly, cross-resistance seems nonspecific for inhibitor scaffolds, a notion that can be exploited in future drug design to evict possible resistance mutations during clinical treatment.

Oncogene (2016) 35, 2518-2528; doi:10.1038/onc.2015.319; published online 14 September 2015

\section{INTRODUCTION}

Mps1 (also known as TTK) is an essential dual-specificity kinase that acts as an important guardian of the fidelity of chromosome segregation. Mps1 has an essential role in the mitotic checkpoint, ${ }^{1-3}$ also referred to as the spindle assembly checkpoint. ${ }^{4}$ An important factor in this regulation is its multiphosphorylation of the essential kinetochore component KNL1. ${ }^{5-7}$ Depletion of Mps1 results in mitotic checkpoint abrogation and cell death within several rounds of cell division. ${ }^{8}$ Interestingly, partial short hairpin RNA-based depletion of Mps1 results in enhanced sensitivity to low doses of the microtubule targeting chemotherapeutic paclitaxel (taxol) in human tumor cells, whereas immortalized human fibroblasts display less sensitivity to this combination. ${ }^{8}$ Reducing Mps1 levels by RNA interference in cells overexpressing Mps1 has been shown to be detrimental to survival, but did not affect cell viability of isogenic untransformed cells. ${ }^{9}$ These observations have drawn the attention of researchers to Mps1 as a potential therapeutic target for cancer therapy. Several Mps1 small-molecule inhibitors have been described to date (reviewed in Lan and Cleveland ${ }^{10}$ and Liu and Winey ${ }^{11}$ ). These compounds often exhibit promising anti-proliferative activity in human cancer cells because of the specific inhibition of Mps1 kinase activity. Among these compounds, NMS-P715, MPI-0479605, Mps-BAY2b and Mps1-IN-3 showed promising results in pre-clinical studies with rodent xenograft models. ${ }^{12-15}$ Apart from these pre-clinical compounds, the small-molecule Mps1 inhibitors reversine and AZ3146 have drawn attention as important tools to decipher Mps1 functions in mitosis. ${ }^{10,16,17}$

The strategy of targeting kinases with small-molecule kinase inhibitors in cancer therapy has been specifically successful to treat cells overexpressing or containing hyperactivated alleles of the tyrosine kinases $B C R-A B L$ and epidermal growth factor receptor (EGFR) (reviewed in Barouch-Bentov and Sauer ${ }^{18}$ ). Although very successful, these treatments have also unveiled that initial drug responses are frequently followed by the acquisition of drug resistance with often complete unresponsiveness to the small-molecule inhibitors. Drug resistance can be due to activation of bypass signaling pathways, but often arises as a consequence of mutations in the targeted kinase that render it insensitive to the inhibitors, leaving the overall activity relatively unaffected. These mutations often occur in a specific residue of the Adenosine triphosphate (ATP)-binding pocket called the 'gatekeeper', so called because the size of the amino-acid side chain at this position determines which nucleotides, ATP-analogs or inhibitors can bind. ${ }^{19}$ For example, the EGFR mutation T790M decrease the $\mathrm{Km}$ of the EGFR for ATP, thus increasing the catalytic efficiency of the kinase. This in turn leads to a diminished relative binding of the ATP-competitive inhibitors gefitinib and erlotinib (reviewed in Chong and Janne ${ }^{20}$ ). In BCR-ABL1, the T315I gatekeeper mutation eliminates a critical hydrogen bond for inhibitor binding and creates a steric clash with the inhibitor imatinib. ${ }^{21}$ Combining mutation analysis and structural biology has allowed for the identification of second-generation inhibitors for BCR-ABL1 and EGFR. These latter inhibitors were designed to specifically target only the gatekeeper-mutated form of the kinase (reviewed in Chong and Janne ${ }^{20}$ and Weisberg et al. ${ }^{22}$ ). Thus, the development of kinase inhibitors can benefit from structural work to guide improved selectivity and specificity of certain inhibitors.

Apart from the inhibitor resistance in tyrosine kinases like EGFR and $B C R-A B L 1$, kinase inhibitor resistance in serine-threonine kinases has also been described recently. The essential mitotic Aurora and Polo-like kinases have drawn attention as potential therapeutic targets for clinical cancer therapy. Girdler et $a l^{23}$ used hypermutagenic colon cancer cells to identify mutations in Aurora $B$ to confer resistance to the inhibitor ZM447439. Wacker et al. ${ }^{24}$ identified mutations in PLK1 to confer resistance to the PLK inhibitor BI2536 by using the same strategy. Interestingly, the identified mutations in these kinases were not at the gatekeeper position but located at other positions in the ATP-binding pocket of these kinases. Similar mutations were described in a study of

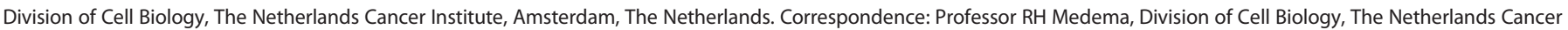
Institute, Plesmanlaan 121, Amsterdam 1066CX, The Netherlands.

E-mail: r.medema@nki.nl

${ }^{1}$ Present address: Department of Genome Dynamics, Lawrence Berkeley National Laboratory, Berkeley, CA, USA

Received 6 May 2015; revised 14 July 2015; accepted 21 July 2015; published online 14 September 2015 
Scutt et al. ${ }^{25}$ that used a computational crystallographic analysis to identify drug-resistant mutations of Aurora A, B and PLK1.

Here we describe the identification and characterization of a variety of mutations in Mps1 that provoke resistance to smallmolecule inhibitors of Mps1. We identify four point mutations in the catalytic kinase domain of Mps1 that give rise to various levels of resistance. In addition, we provide evidence that an Mps1 mutation found in a human tumor sample confers resistance to Mps1 inhibitors. We furthermore tested if the identified mutations resulted in cross-resistance to different classes of Mps1 inhibitors. We find that the mutations confer resistance to only a subset of inhibitors, providing important insights for future drug design to prevent the development of resistance during drug therapy.

\section{RESULTS}

To determine whether human cancer cells can develop resistance to Mps1 inhibitors, we aimed at identifying the most potent compound to use for our selection procedure. The three cancer cell lines HCT-116, DLD-1 and U2OS were exposed to increasing concentrations of the known Mps 1 inhibitors NMS-P715, ${ }^{12} \mathrm{MPI}-$ $0479605,{ }^{15}$ reversine ${ }^{17}$ and a derivative of NMS-P715, hereafter referred to as compound-5 (Cpd-5) ${ }^{26}$ (Supplementary Figure 1). The treatment with different inhibitors reduced cell viability in all cases, nevertheless with different grades of sensitivity (Supplementary Figures 2a-c). NMS-P715 shows the weakest effects of all tested inhibitors with an $I_{50}$ higher than $150 \mathrm{~nm}$ (Supplementary Figures 2a-c). Reversine and MPI-0479605 exhibit a slightly more potent effect with $\mathrm{IC}_{50}$ around 63 to $153 \mathrm{~nm}$.
Cpd-5 shows the strongest effect of the four tested inhibitors with an $\mathrm{IC}_{50}$ of 20-25 nm (Supplementary Figures 2a-c). When used in in vitro kinase assays using recombinant Mps 1 kinase domain (519-808 aa), Cpd-5 showed increased potency ( $\mathrm{IC}_{50}$ of $5.8 \mathrm{~nm}$ ) compared with NMS-P715 ( $\mathrm{IC}_{50}$ of $\left.71.3 \mathrm{nM}\right)$, suggesting that the inhibitory effect on cell survival is because of the inhibition of Mps1 (Supplementary Figure 2d). For further validation of Cpd-5 as an Mps1 inhibitor, we used HeLa cells expressing fluorescently tagged histone H2B (H2B-YFP). Cpd-5 inhibits the proliferation of these HeLa cells with an $\mathrm{IC}_{50}$ of $28 \mathrm{~nm}$ (Supplementary Figure 3a). In order to determine the effects of selective Mps1 inhibition by Cpd-5 on mitotic checkpoint activity, we treated HeLa cells with the microtubule poison nocodazole in the absence and presence of Cpd-5 (Figure 1a). HeLa cells treated with nocodazole remained arrested for $>720 \mathrm{~min}$ after nuclear envelope breakdown. Simultaneous administration of $100 \mathrm{~nm}$ Cpd-5 led to mitotic exit in $94 \%$ of the cells within $60 \mathrm{~min}$ after nuclear envelope breakdown, indicating that $\mathrm{Cpd}-5$ efficiently abrogates the mitotic checkpoint at concentrations that effectively inhibit the kinase activity of Mps1. In addition, Cpd-5 administration alone resulted in a decrease in the time spent in mitosis with nearly $100 \%$ of HeLa cells initiating anaphase within 15 min (50 and $100 \mathrm{~nm} \mathrm{Cpd-5)}$ as compared with $0 \%$ of dimethylsulfoxide (DMSO)-treated cells initiating anaphase in the same time frame (Figure 1b). The average time spent in mitosis decreased from $52.3 \mathrm{~min}$ ( $\pm 33.1 \mathrm{~min}$ ) in DMSO-treated cells to $16.7( \pm 2.6 \mathrm{~min})$ in $50 \mathrm{~nm}$ and 15.7 $( \pm 2.3 \mathrm{~min})$ in $100 \mathrm{~nm}$ Cpd-5-treated cells (Figure $1 \mathrm{~b}$ ). This decreased timing was associated with an increase in the amount of missegregating chromosomes from $\sim 20 \%$ in DMSO-treated a

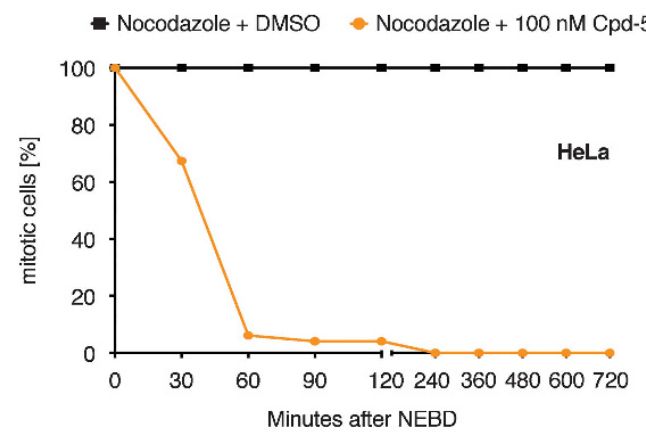

b

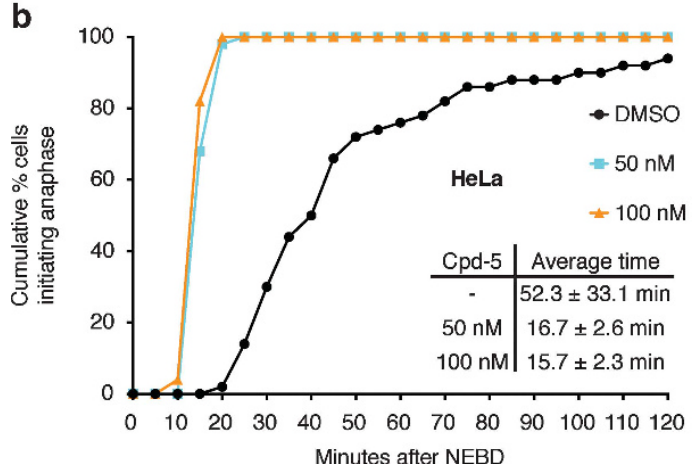

c
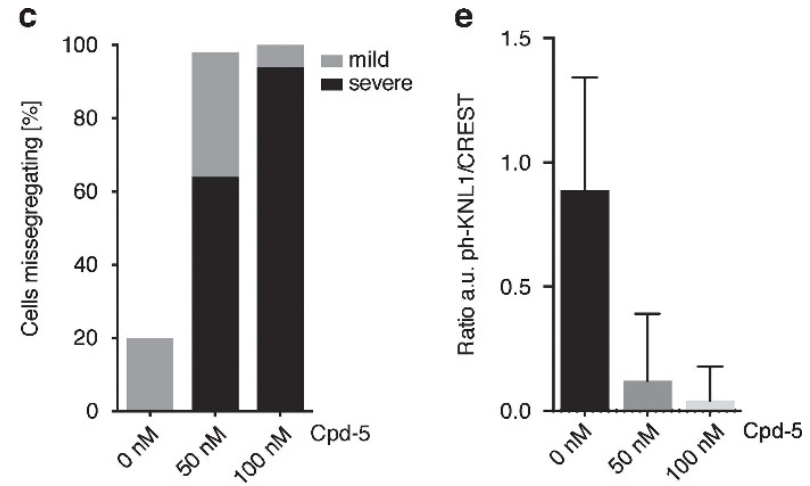

d
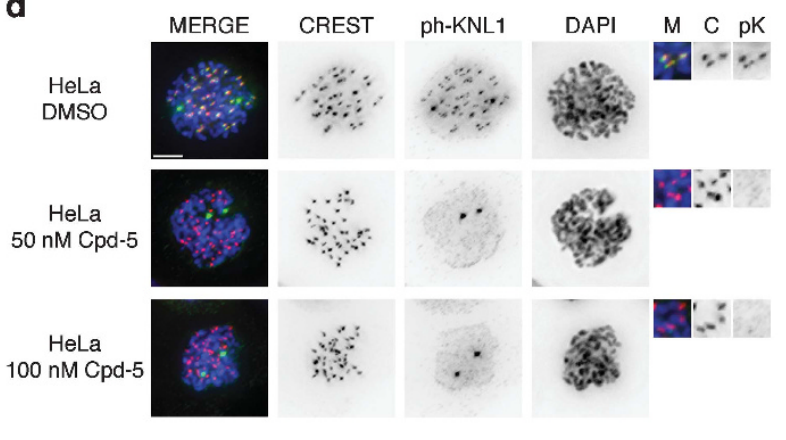

Figure 1. Cpd-5 administration abrogates the mitotic checkpoint and leads to cell death. (a) Live cell imaging of HeLa histone H2B-YFP cells treated with nocodazole $\pm \mathrm{Cpd}-5$. Shown is the time from nuclear envelope breakdown (NEBD) to the decondensation of DNA. Hundred cells of each cell population were counted. (b) Cumulative percentage of HeLa histone H2B-YFP cells initiating anaphase after administration of DMSO or 50/100 nM Cpd-5. Time refers to the duration between NEBD and anaphase initiation. Fifty cells of each cell population were analyzed. (c) Quantification of chromosome missegregations. Two phenotypes are depicted; anaphases with mild missegregations (up to 3 chromosomes) and severe missegregations (>3 chromosomes). Fifty cells per condition were analyzed. (d) Representative images of HeLa cells treated with DMSO, 50 or $100 \mathrm{nM}$ Cpd-5 and immunostained for phosphorylated KNL1 (ph-KNL 1) ${ }^{40}$ and CREST. DNA was visualized with 4,6-diamidino-2-phenylindole (DAPI). (e) Depicted are the relative ratios of the fluorescence intensities of ph-KNL1 and CREST kinetochore signals. Two hundred kinetochores were scored for each condition. 
cells to nearly $100 \%$ after 50 and $100 \mathrm{~nm}$ Cpd-5 administration (Figure 1c). The severity of segregation errors was increased when comparing 50 with $100 \mathrm{~nm}$ Cpd-5 (from 60\% to 95\%) although the time spent in mitosis did not decrease further $(16.7 \mathrm{~min}$ in $50 \mathrm{~nm}$ compared with $15.7 \mathrm{~min}$ in $100 \mathrm{~nm}$ ) (Figure 1c). Furthermore, we tested the ability of Cpd-5 to prevent the Mps1-specific phosphorylation of the MELT repeats in the kinetochore protein KNL1. ${ }^{6,7}$ Administration of 50 and $100 \mathrm{~nm}$ completely depleted the level of phosphorylated KNL1 at kinetochores (Figures 1d and e). These data indicate that Cpd-5 administration leads to cell death because of the increase in missegregations as a result of abrogated mitotic checkpoint and improper chromosome alignments, a phenotype previously described for knockdown as well as chemical inhibition of Mps1 (reviewed in Liu and Winey ${ }^{11}$ ).

\section{Cells acquire resistance to $\mathrm{Cpd}-5$ through selective mutation of Mps1}

Having established Cpd-5 as a bona fide Mps1 inhibitor, we next determined if human cancer cells could develop resistance to Cpd-5. To this end, we made use of mismatch repair-deficient (and therefore hypermutagenic) colorectal cancer cell lines HCT-116 and DLD-1, ${ }^{27}$ as well as chromosome instable cell lines U2OS and HeLa. This strategy has been previously used successfully with HCT-116 cells to obtain resistant cell lines against the Aurora B inhibitor ZM447439. ${ }^{23}$

All cell lines were treated with lethal concentrations of Cpd-5 (up to $50 \mathrm{~nm}$ ) over a period of 3 weeks. After treatment, we obtained nine independent HCT-116, four independent HeLa and one DLD-1 Cpd-5-resistant cell lines. These 14 cell lines were tested in a colony formation assay, and three HCT-clones, one DLD-1 clone and one HeLa-clone showed survival upon

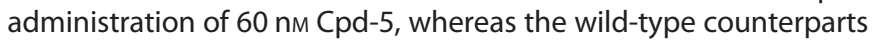
were not able to survive at this concentration (Figure 2a). Sequencing of Mps1 complementary DNAs (cDNAs) derived from these clones revealed that these had acquired mutations in the Mps1 gene (Figure 2b). All of the identified mutations map to the highly conserved kinase domain of Mps1 (Supplementary Figure 4). Besides the cell lines that contained mutations in Mps1, we also identified cell lines without mutations that were partially resistant to $\mathrm{Cpd}-5$. This points to possible mechanisms of resistance that do not involve mutations in Mps1 that will require further study. Nonetheless, these data show that cells can acquire resistance to Mps1 inhibitors via mutations in the Mps1 kinase domain.

Next, we sought to determine the $\mathrm{IC}_{50}$ of $\mathrm{Cpd}-5$ in the mutant cell lines (Figure 2c). HCT-I531M had a $10.2 \mathrm{x}$ higher $\mathrm{IC}_{50}$ than HCT-116 control cells. The two HCT-C604Y cell lines exhibited an even higher tolerance rate for $\mathrm{Cpd}-5$ with an $18.8 \mathrm{x}$ and 18.1x higher $I_{50}$ for Cpd-5 than the HCT-116 counterpart. The homozygous S611R mutation in DLD-1 cells exhibited a 10x higher $\mathrm{IC}_{50}$ for Cpd-5 than DLD-1 cells. The homozygous I598F mutation showed the weakest increase in $\mathrm{IC}_{50}$ change of all mutants with only a 2.6x higher tolerance for Cpd-5 (Figure 2c, Supplementary Figure 5). Western blot analysis of Mps1 protein levels indicated that the mutations do not influence the stability or expression of Mps1 (Supplementary Figure 6a).

\section{Mutated Mps1 variants confer resistance to $\mathrm{Cpd}-5$}

As an alternative measure for the effect of $\mathrm{Cpd}-5$ on mutated Mps1, we asked whether the mutant cell lines arrest in mitosis in a mitotic checkpoint-dependent manner in the presence of high doses of $\mathrm{Cpd}-5$. Although the relative mitotic indexes of parental HCT-116, and DLD-1 control cells dropped by $60 \%$ and $70 \%$ after 16-h treatment with $30 \mathrm{~nm}$ Cpd-5 and nocodazole (microtubule destabilizing drug), the mutant counterparts DLD-1-S611R, HCT-I531M and both HCT-C604Y were still in mitosis at higher concentrations of Cpd-5 (200 and $400 \mathrm{~nm}$ ) (Figure 3a). Thus, the trend seen in the colony formation assays (Figure $2 \mathrm{c}$ ) was mirrored in these mitotic checkpoint assays, with the C604Y mutation being most resistant to Cpd-5. Unfortunately, in our hands, HeLa cells were not suitable for this fixed cell-based assay and therefore we performed live cell imaging to determine if the $1598 \mathrm{~F}$ mutation also sustains mitotic checkpoint function in the presence of Cpd-5. Nocodazole caused both the HeLa and HeLa-I598F cells to arrest in mitosis for $>1200$ min (Figure 3b). Cpd-5 administration led to a significant decrease in average mitotic timing in HeLa cells, but HeLa-I598F cells were more refractory to checkpoint inactivation by Cpd-5 (Figure 3b). Complete checkpoint override was seen at $100 \mathrm{~nm} \mathrm{Cpd-5}$ in HeLa versus $200 \mathrm{~nm} \mathrm{Cpd-5}$ in its mutated counterpart (Figure $3 \mathrm{~b}$ ). This twofold difference in sensitivity is in agreement with the observed increase of $\mathrm{IC}_{50}$ determined in the viability assays (Figure $2 \mathrm{c}$ ).

\section{In vitro activity of Mps1 mutants}

To determine the effect of the mutations on the catalytic activity of Mps1, we performed in vitro kinase assays with recombinant kinase domain of mutated and non-mutated Mps1 using KNL1 as a substrate. ${ }^{28}$ All mutated kinases showed increased resistance to Cpd-5 in vitro with the C604Y displaying most resistance, the S611R displaying only minor resistance (Supplementary Figure 7). At $400 \mathrm{~nm}$, only Mps1-C604Y retained kinase activity with only a $40 \%$ reduction in target phosphorylation. Thus, these mutations render Mps1 more resistant to $\mathrm{Cpd}-5$, but they can be inhibited at higher doses. As the total level of KNL1 phosphorylation was similar among the mutant forms, we conclude that the mutants are not hyperactive, but likely have reduced affinity for Cpd-5 when compared with the wild-type counterpart (Supplementary Figure 7).

\section{Modeling of mutations in the Mps1 crystal structure}

Next, we modeled the identified mutations into the crystal structure of the Mps1 kinase domain, complexed to NMS-P715. ${ }^{12}$ $1531 \mathrm{M}, \mathrm{C604Y}$ and S611R are located in the ATP-binding pocket, whereas I598F is located further away in the N-terminal lobe of the kinase domain in an area called the hydrophobic spine ${ }^{29}$ (Figure 4a). 1531 is located at the top of the ATP-binding pocket and has hydrophobic stacking interactions with the phenyl-ring in NMS-P715 (Figure 4a). Replacement with methionine in the $1531 \mathrm{M}$ mutation, although equally hydrophobic, is expected to disrupt these interactions, although without inducing van der Waals clashes with binding of NMS-P715. The situation is much more marked with residue C604, which has interactions with the trifluoro-methoxy group of NMS-P715 and the N18 nitrogen atom that connects the NMS-P715 ring systems. These are disrupted by replacement of $\mathrm{C604}$ with a bulky phenyl group in the C604Y mutation, which is expected to be incompatible with binding of the trifluoro-methoxy group in NMS-P715 (Figure 4b). Finally, residue $\mathrm{S} 611$ has no direct interactions with NMS-P715, but maintains a strong hydrogen bond with D608, which is important for the structural integrity of the hinge region that connects the $\mathrm{N}$ - and C-terminal lobes of the kinase domain. The S611R mutation, however, stereochemically interferes with binding of the aniline and piperidine moieties of NMS-P715, but can maintain a hydrogen bond to D608.

Interestingly, the residue 1598 has no direct role in NMS-P715 binding, as it is located $12.4 \AA$ from the nearest inhibitor atom. Although bulkier, the phenylalanine side chain in the $1598 \mathrm{~F}$ mutation can be accommodated in the hydrophobic environment where it is placed, showing no direct stereochemical clashes (Figure 4c). However, residue 1598, being placed in the hydrophobic spine, is relatively close to the catalytic pair E571 and K553, which in the crystal structure are at $5.7 \AA$ distance, indicating a catalytically inactive conformation. ${ }^{30}$ Therefore, it is expected that structural rearrangements take place in this region during the 
a

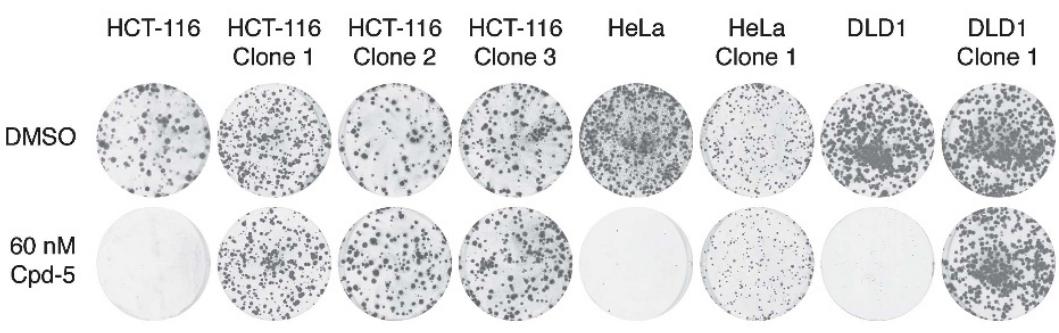

b
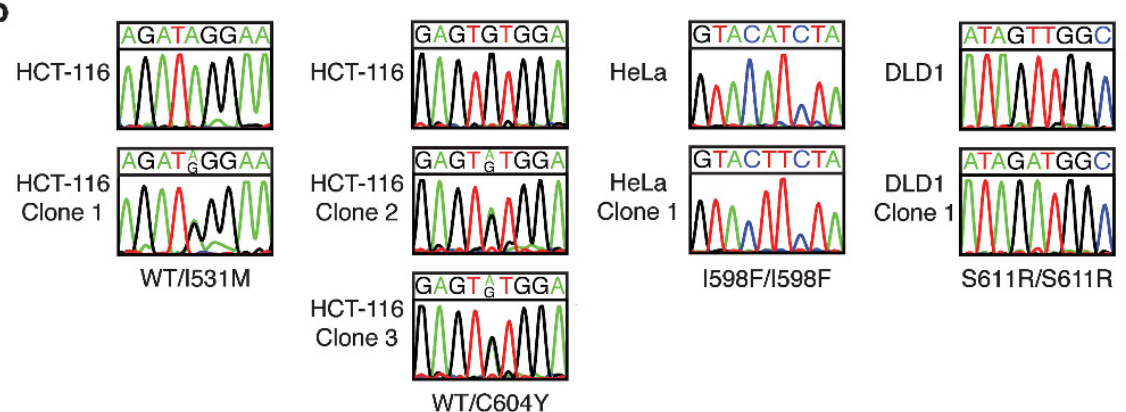

C

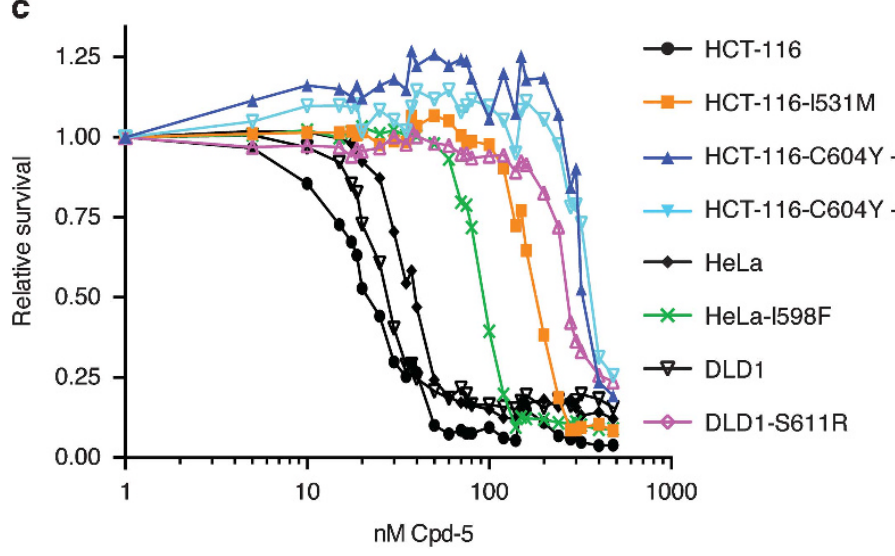

$\underline{\mathrm{IC} 50}$

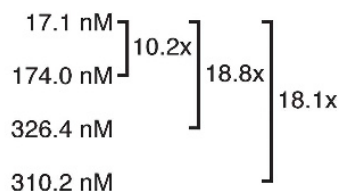

$\left.\begin{array}{l}35.1 \mathrm{nM} \\ 89.2 \mathrm{nM}\end{array}\right] 2.6 \mathrm{x}$

$\left.\begin{array}{c}24.8 \mathrm{nM} \\ 248.8 \mathrm{nM}\end{array}\right] 10.0 \mathrm{x}$

Figure 2. Isolation of Cpd-5-resistant cell lines identifies Mps1 mutations. (a) Crystal violet staining of six-well plate colony formation assays with $\approx 500$ cells per well grown for 14 days. (b) DNA sequence traces of Mps 1 cDNA in parental and Cpd-5-resistant cell lines. (c) Relative survival plots of wild-type and mutant clones treated for 5 days with increasing concentrations of Cpd-5. Shown is the average of three independent experiments and the calculated $I C_{50}$. For better visibility, the s.d. was excluded from this graph.

catalytic activation of Mps1 and the $1598 \mathrm{~F}$ mutation could interfere with this flexibility (Figure 4c).

Expression of mutated Mps1 confers resistance to Mps1 inhibitors To demonstrate that the identified Mps1 mutations are sufficient to cause drug resistance, we ectopically expressed the mutant kinases as LAP-tagged fusions in U2OS cells, a strategy successfully used previously with the Mps1 gatekeeper mutation M602Q. ${ }^{31}$ Stable cell lines ectopically expressing LAP-Mps1 showed similar expression across all used constructs (Supplementary Figure 6b). Although LAP-Mps1 was not able to increase the ability of cells to withstand higher concentrations of Cpd-5 (31.9 nM compared with $33.2 \mathrm{~nm})$, the mutant versions of LAP-Mps1 increased the resistance of these cells to $\mathrm{Cpd}-5$ in a similar manner as seen before for the original mutant cell lines (Figure 5a; Supplementary Figure 8a). These results confirm that the identified Mps1 mutations indeed render the cells resistant to $\mathrm{Cpd}-5$ with the C604Y mutation having the strongest effect on survival of the U2OS cells. In agreement with the increased cell survival, we find that the mutant LAP-Mps1 expressing cells could maintain a checkpoint-dependent arrest in the presence of $100 \mathrm{~nm}$ Cpd-5 (Figure 5b). Importantly, these results show that the anti-proliferative effects of Cpd-5 are directly because of inhibition of Mps1, and not because of off-target effects, at least not at doses below $300 \mathrm{~nm}$.

To demonstrate that endogenous expression of a mutant allele can confer resistance to Mps1 inhibitors, we used CRISPR/Cas9mediated genome editing ${ }^{32,33}$ to engineer the $\mathrm{C} 604 \mathrm{Y}$ mutation into the HeLa histone H2B-YFP cell line for a straightforward analysis of the cellular phenotypes. Interestingly, the C604 position in Mps1 has one additional incentive because a search of the COSMIC (catalog of somatic mutations in cancer) database ${ }^{34}$ revealed that it was found to be mutated into $604 \mathrm{~F}$ in a tumor sample of a patient with lung adenocarcinoma. To introduce the C604F and C604Y mutations, we designed an oligonucleotide with the desired mutation and two silent mutations to serve as a template for homologous recombination after the Cas9-mediated DNA double-strand break formation (Figure 6a). The selection with $80 \mathrm{~nm}$ Cpd-5 only yielded clones in the presence of both the Cas9/gRNA and the oligonucleotide (Figure 6b). Genomic DNA and Mps1 cDNA derived from individual cell clones was sequenced for the presence of the desired point mutation and the silent mutations (Figure $6 c$ ). After the confirmation of the successful genome-editing approach, we characterized the 


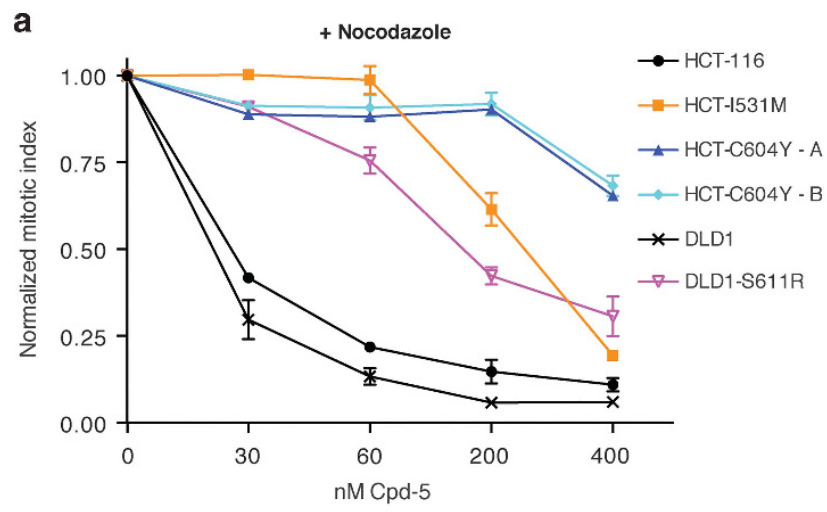

b

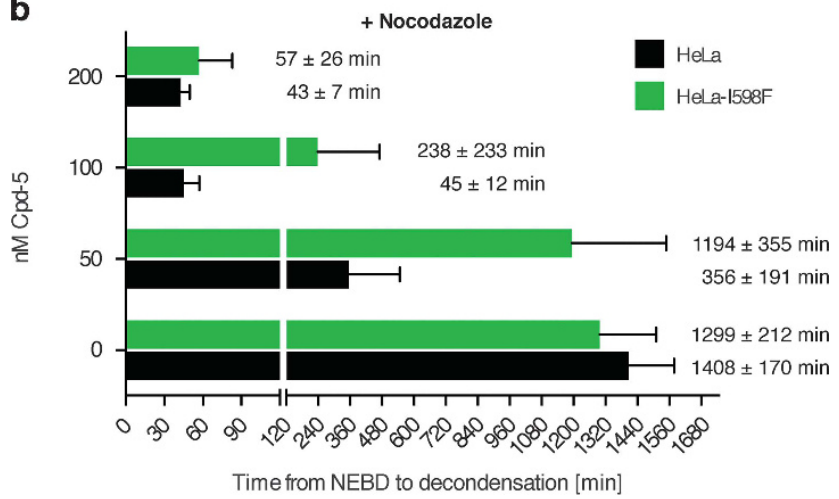

Figure 3. Mps1 mutations restore mitotic checkpoint function. (a) Cells were treated with nocodazole and various $\mathrm{Cpd}-5$ concentrations for $16 \mathrm{~h}$, fixed and immunostained for phospho$\mathrm{H} 3 \mathrm{~S} 10$. Mitotic indexes were calculated as the fraction of phospho-H3S10-positive cells over total cells. Shown are the normalized mitotic indexes and s.d. for various concentrations of three independent experiments. (b) Live cell imaging of HeLa and HeLa-I598F histone H2B-YFP cells treated with nocodazole \pm various Cpd-5 concentrations. Shown is the average time from nuclear envelope breakdown (NEBD) to the decondensation of DNA from 100 cells in each condition.

mutant clones for their sensitivity against Cpd-5. The HeLa-C604Y had a $12.3 \mathrm{x}$, and the $\mathrm{C} 604 \mathrm{~F}$ a $6.3 \mathrm{x}$ higher $\mathrm{IC}_{50}$ for $\mathrm{Cpd}-5$ than the parental HeLa cells (Figure 6d). To further characterize the C604Y and $\mathrm{C} 604 \mathrm{~F}$ clones, we performed live cell imaging experiments. Although the average time HeLa cells spent in mitosis decreased drastically after administration of $100 \mathrm{~nm} \mathrm{Cpd-5}$ (see also Figure 2b), HeLa-C604F and C604Y cells stayed merely unaffected even at 200 nм of Cpd-5 (Supplementary Figure 9a). The decreased mitotic timing in the parental HeLa cells was associated with $100 \%$ severe segregation errors (Figure 6e). Although C604F cells missegregated already with a rate of $70 \%$ at $200 \mathrm{~nm}$ Cpd-5, most of the errors were only mild segregation errors (Figure 6e). This increased to almost $100 \%$ severe segregations errors after the administration of $400 \mathrm{~nm}$ Cpd-5, a concentration that was shown to be lethal for the cells in the growth assay (Figures $6 \mathrm{~d}$ and e). Similar to the growth assay, with the C604Y cell line showing a $2 x$ higher IC50 as the C604F cell line, also the errors in chromosome segregation were less severe in this cell line. In fact, at $400 \mathrm{~nm}$ Cpd-5 administration, HeLa-C604Y cells exhibited a maximum of $70 \%$ and mostly mild segregation errors, comparable to what HeLa-C604F cells encountered at $200 \mathrm{~nm} \mathrm{Cpd-5}$ (Figure 6e).

These data confirm that the $\mathrm{C} 604 \mathrm{Y}$ mutation is indeed the causal mutation for the Cpd-5 resistance in HCT-116-C604Y cells. The fact that also the C604F substitution in Mps1 confers Cpd-5 resistance shows that inhibitor-resistant mutations in human tumor material, similar to the ones we have obtained in cultured cell lines, can be present.

Mutations in Mps1 confer resistance to other small-molecule Mps1 inhibitors

Given the fact that a variety of potent and specific Mps1 inhibitors have been described, ${ }^{10,11}$ we were interested to see if the identified mutations could confer resistance to NMS-P715, ${ }^{12}$ Mps1-IN-3, ${ }^{14}$ MPI-0479605, ${ }^{15}$ AZ3146 ${ }^{\text {(ref. 16) }}$ and reversine ${ }^{17}$ (Supplementary Figure 1). All identified mutations conferred resistance to NMS-P715 (which has a similar chemical structure as Cpd-5), and AZ3146 (Supplementary Figures 10a and b; Table 1). The HCT-I531M and HeLa-I598F cell lines showed only a slight decreased sensitivity toward Mps1-IN-3, whereas the other mutations showed increased resistance (Supplementary Figure 10c; Table 1). The I598F mutation also failed to confer significant resistance to $\mathrm{MPI}-0479605$ and reversine compared with the nonmutated parental HeLa-cell line (Figures $7 a$ and $b$; Table 1). Interestingly, the C604Y (and C604F) mutation that represents the most Cpd-5-resistant allele, and also shows full resistance to MPI-0479605, retained full sensitivity to reversine, whereas all other mutations caused resistance to reversine (Figures $7 a$ and $b$; Table 1). In order to investigate the reversine sensitivity of the C604Y and C604F mutants in more detail, we performed live cell imaging. HeLa-C604Y and HeLa-C604F in fact exhibited a hypersensitivity to reversine, translating into shortening of mitosis and increase of segregation errors at doses that keeps the parental cells almost unaffected (Supplementary Figures $9 \mathrm{~b}$ and c; $75 \mathrm{~nm}$ $+150 \mathrm{~nm}$ ). Also, HCT-C604Y cells could not maintain a mitotic arrest in the presence of reversine in stark contrast to HCT-I531M cells (Supplementary Figure 9d). In addition, cell survival assays with cell lines expressing LAP-tagged Mps1 mutants exhibited the same sensitivity pattern (Supplementary Figures $9 e$ and f). This indicates that cell death in Mps1-C604Y/F mutated cells is caused by specific inhibition of Mps1 and not via inhibition of a secondary essential target.

These results show that except for the S611R mutation, which conferred resistance to all tested inhibitors (Table 1), specific mutations confer resistance only to specific inhibitors. In case of reversine and $\mathrm{MPI}-0479605$, this is of particular interest because reversine is a des-methyl derivative of MPI-0479605 at the C-2-aniline position, but exhibits a completely different spectrum of resistant mutations in the light of Mps1 inhibition.

\section{DISCUSSION}

Mps1 inhibitors as potential anticancer therapy reagents

Here, we have identified several mutations in Mps1 that provide resistance to Mps1 inhibitors. Mutations in the target kinase should result in enhanced kinase activity in the presence of the inhibitor and this can be achieved by hyperactivation of the kinase or by selective inhibition of inhibitor binding, leaving ATP-binding relatively unaffected. Our data provide no evidence for effects of the identified mutations on kinase activity or stability, suggesting that they must affect inhibitor binding. Similar studies in Aurora and Polo-like kinases have identified several residues that confer resistance to small-molecule inhibitors. In Aurora B, mutation of $\mathrm{Y} 156 \mathrm{H}$ and G160V can give rise to inhibitor resistance. ${ }^{23}$ Interestingly, sequence alignment of the kinase domains of Aurora B and Mps1 shows that Aurora Y156 aligns with C604 in Mps1. G160 on the other hand would be equivalent to D608 in Mps1, which was not identified with our strategy. However, this residue may be of importance, as the equivalent of Aurora B G160 has also been found to be a critical residue in Aurora A (G216) in terms of inhibitor resistance. ${ }^{35}$ Mutation of the adjacent residue T217 in Aurora A has also been successfully used to investigate inhibitor 
a

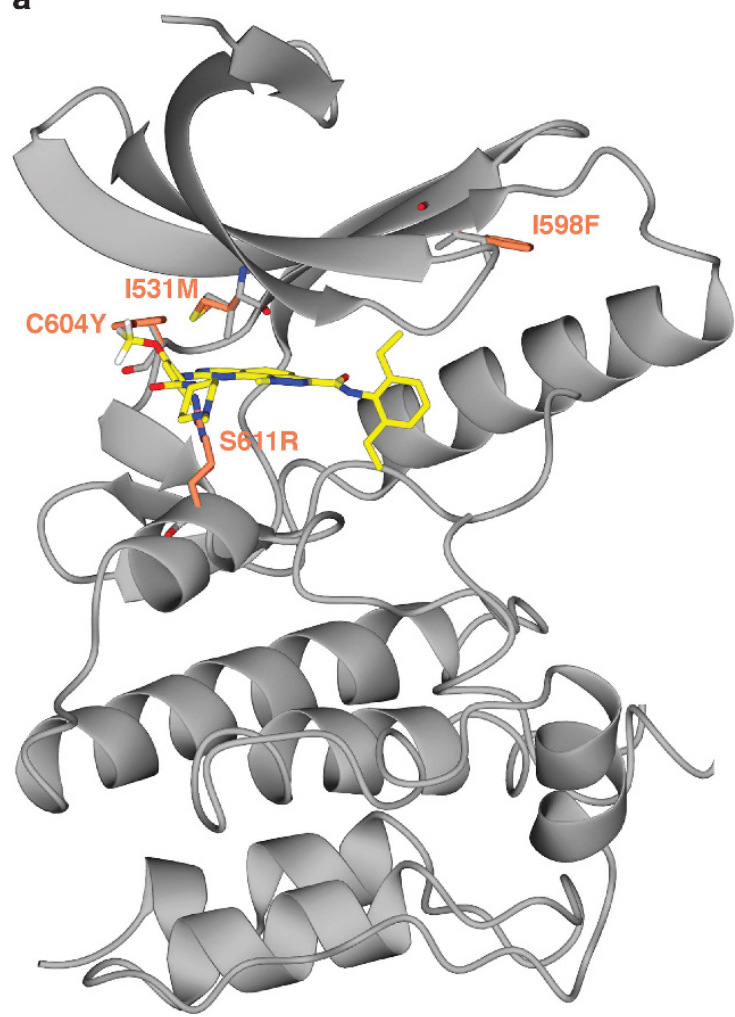

b

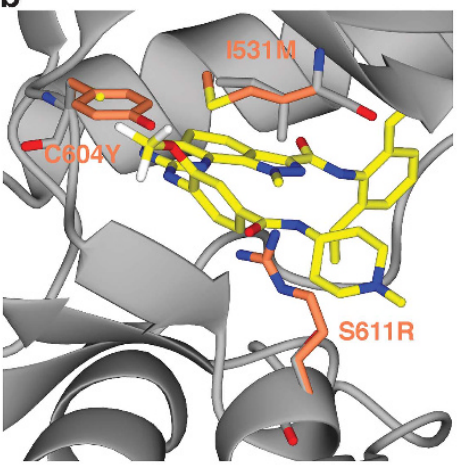

C

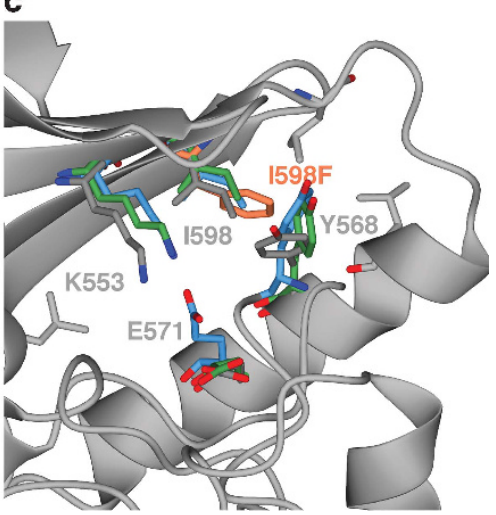

Figure 4. Location of the Mps1 mutations in the crystal structure of the Mps1 kinase domain complexed to NMS-P715. ${ }^{12}$ NMS-P715 is shown in yellow, the wild-type residues in grey, and mutated residues in coral. (a) Overall location of the mutations in the kinase domain. (b) Detail of the ATP-binding pocket with the 1531M, 1598F, C604Y mutations. (c) Detail of the hydrophobic spine with the I598F mutation. Shown in addition is an overlay of the Mps1 crystal structure with NMS-P715 12 (grey), with the crystal structures of an ATP bound ${ }^{30}$ (green) and a pyrrolopyridine inhibitor $^{39}$ (blue). Only one main chain is shown for clarity. The I598F mutation is shown in coral.

resistance to the Aurora A inhibitors MLN8054 and MLN8237. ${ }^{36}$ The latter mutations were, however, not identified in cell lines but mutated based on structural predictions. In light of Polo-like kinase inhibitor resistance, the mutation R136G was identified in an experimental approach based on structural features, ${ }^{25}$ as well as in an in vivo study. ${ }^{24}$ Significantly, the residue R136 is the equivalent to G160 in Aurora B. These data provide evidence that these are important residues in the kinases in the light of inhibitor resistance. It would be interesting to investigate if the D608 mutation in Mps1 would also confer resistance to specific Mps1 inhibitors.

In addition to these Mps1 mutations, we also identified resistant cell clones that do not contain mutations in Mps1, pointing to alternative resistance mechanisms that will require further analysis.

From their position within the kinase, I531M, C604Y and S611R are expected to interfere directly with binding of NMS-P715. C604Y and S611R abrogate binding contacts and insert van der Waals clashes with NMS-P715, whereas I531M disrupts favorable hydrophobic stacking interactions with NMS-P715. The mutation $1598 \mathrm{~F}$, on the other hand, is located far away from the ATP-binding site, but its effect on inhibitor binding may involve a conformational change through a rearrangement of E571 and K553.

Kumar et al..$^{38}$ used computational modeling to fit MPI-0479605 into the Mps1 crystal structure based on reversine-bound Aurora kinase crystal structures (PDB-code: 2VGO). ${ }^{37}$ I531 in Mps1 was predicted to be involved in a favorable van der Waals interaction with the ortho-substituted aniline at the purine C2 position in both reversine and MPI-0479605 respectively. Thus, the mutation to methionine may indeed lead to a reduction of this favorable interaction, making the mutant protein less receptive for the two inhibitors.
It is therefore remarkable that the C604Y mutation has such a tremendous effect on MPI-0479605 sensitivity, whereas reversine retains full activity toward C604Y. Reversine is a des-methyl derivative of MPI-0479605 at the C-2-aniline position, which is at the position of the trifluoro-methoxy-moiety in NMS-P715. Thus, the C604Y specifically blocks inhibitors with bulky modifications at the C-2-aniline position, such as NMS-P715, but also MPI-0479605, and $\mathrm{Cpd}-5$, whereas leaving inhibitors without such modifications, such as reversine, unaffected.

One mutation that exhibits increased resistance against all investigated inhibitors is the S611R mutation. Particularly, the efficacy of reversine and MPI-0479605 is completely negated in S611R-mutated cells. Probably the aniline-morpholine moieties of $\mathrm{MPI}-0479605$ and reversine bind at the same position as the chemically similar aniline-piperidine moiety of NMS-P715, which is blocked by the S611R mutation. However, as MPI-0479605 and reversine are smaller molecules, they probably depend more on this interaction than NMS-P715, which has more additional binding contacts, explaining the relatively large impact of this mutation on MPI-0479605 and reversine binding.

The effects of the 1598F mutation are much less pronounced compared with the other mutations, possibly as a result of its distance from the ATP-binding site. An overlay of the structure of Mps1 in complex with NMS-P715 bound, ${ }^{12}$ with Mps1 bound to ATP $^{30}$ and a recent structure in which the K553/E571 catalytic pair has a more catalytically competent conformation, ${ }^{39}$ shows structural variability particularly in the area around Y568, neighboring the mutated I598. As Mps1 inhibitors exert (part of) their effect through interfering with the K553/E571 catalytic pair, ${ }^{30}$ it is not unlikely that the I598F mutation may limit Y568 flexibility, 

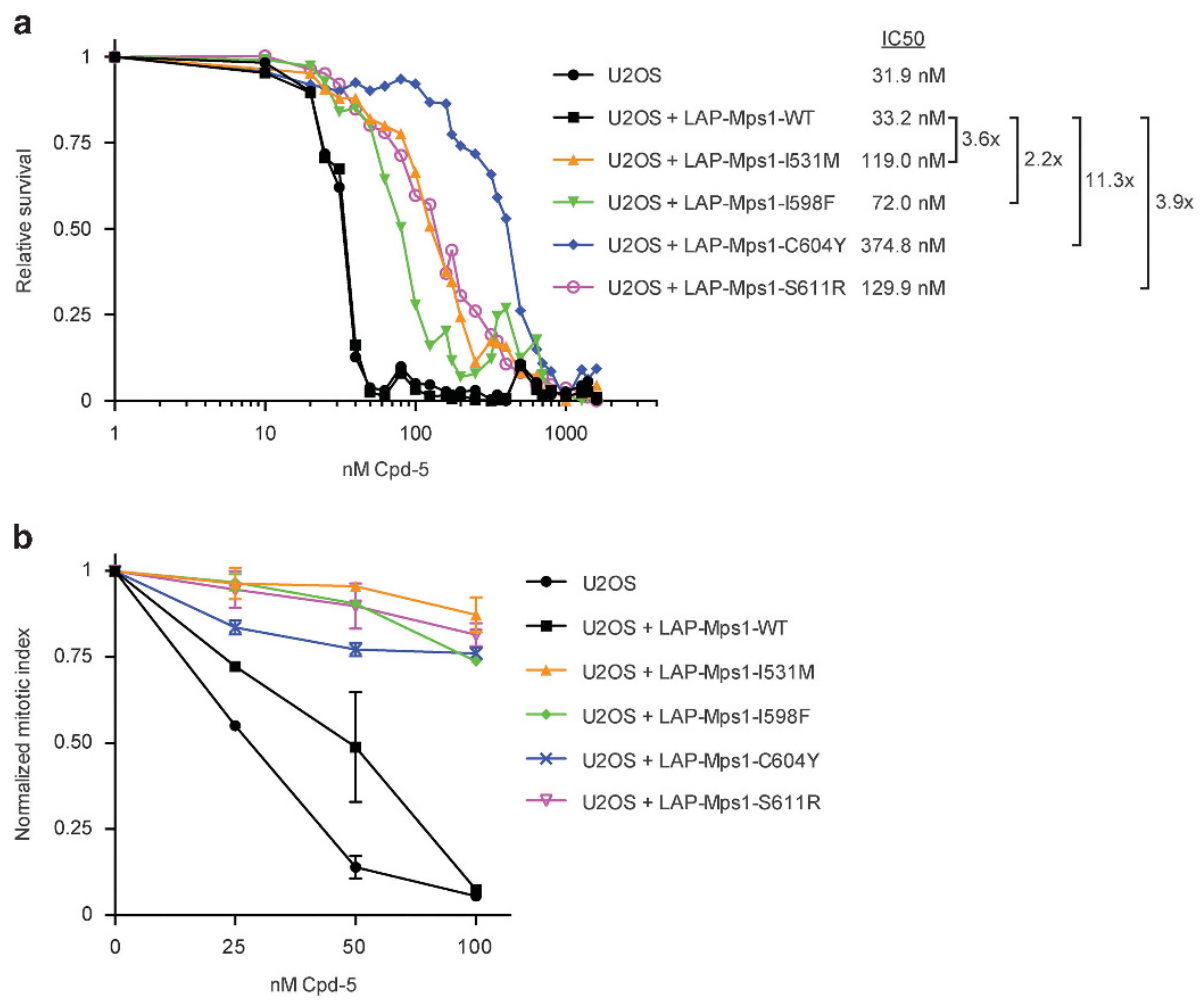

Figure 5. Ectopic expression of mutated Mps1 confers resistance to Cpd-5. (a) Relative survival plots of U2OS cells stably expressing LAP-tag fusions of either Mps1 or mutated Mps1 treated for 5 days with increasing concentrations of Cpd-5. Shown is the average of three independent experiments and the calculated $I C_{50}$. For better visibility, the s.d. were removed from the graph. (b) Cells were treated with nocodazole and various $\mathrm{Cpd}-5$ concentrations for $16 \mathrm{~h}$, fixed and immunostained for phospho-H3S10. Mitotic indexes were calculated as the fraction of phospho-H3S10-positive cells over total cells. Shown are the normalized mitotic indexes and s.d. for various concentrations of three independent experiments.

in turn limiting the ability of the inhibitors to disrupt the K553/ E571 catalytic pair.

In conclusion, we have shown that the four identified mutations have different effects on the resistance to various Mps1 inhibitors. Our work shows that mutations in Mps1, which render cells insensitive to a specific inhibitor, may still be targetable by a different Mps1 inhibitor scaffold. It is therefore advisable to intensify the search for additional Mps1 mutations and use the here identified mutations as de novo drug targets to identify new inhibitor scaffolds, which can target these mutations. The example of the $\mathrm{C} 604 \mathrm{Y}$ response to MPI-0479605 and reversine is the perfect example to justify such a strategy.

The mutations we have identified here also provide powerful tools to determine whether the antitumor effects and toxicity profiles of inhibitors seen in rodent xenograft models are the result of Mps1 inhibition or of an off-target effect. In addition, our data indicate that drug resistance is likely to occur when using the available Mps1 inhibitors, but highlight the possibility that this problem may be mitigated through further drug optimization and clever combinations of the already available Mps1 inhibitors.

\section{MATERIALS AND METHODS}

Cell culture and reagents

All cell lines were grown in Dulbecco's modified Eagle's medium (Lonza, Basel, Switzerland), supplemented with $6 \%$ fetal calf serum (Clontech, Mountain View, CA, USA), $50 \mu \mathrm{g} / \mathrm{ml}$ penicillin-streptomycin (Invitrogen, Waltham, MA, USA) and $2 \mathrm{~mm}$ L-glutamine (Lonza). Thymidine ( $2.5 \mathrm{~mm}$ ) and nocodazole $(200 \mathrm{ng} / \mathrm{ml})$ were purchased from Sigma (St Louis, MO, USA). HeLa cells stably expressing H2B-YFP were created using retroviral infection with pBabe-H2B-YFP (kind gift from Dr Susanne Lens, University Medical Center Utrecht, The Netherlands). Cell lines were selected with $5 \mu \mathrm{g} / \mathrm{ml}$ blasticidine (Sigma). U2OS cells stably expressing LAP-Mps1 were infected with retrovirus carrying pBabe-LAP-Mps1 and were selected with $5 \mu \mathrm{g} / \mathrm{ml}$ blasticidine. LAP-Mps 1 1531M, I598F, C604Y and S611R were created by site-directed mutagenesis PCR. All cell lines were tested negative for Mycoplasma contamination.

\section{Antibodies}

The following antibodies were used: phospho-histone H3-Ser10 (\#06-570, Merck Millipore, Billerica, MA, USA), penta-His (\#34660, Qiagen, Venlo, Netherlands), Mps1-NT (\#05-682, Merck Millipore), CREST (\#15-235-0001, Antibodies Inc., Davis, CA, USA). Phospho-KNL1 MELT13/17 was a kind gift from Geert Kops. ${ }^{40}$

\section{Proliferation/colony formation assay}

Cells ( 1500 per 96-well; $\sim 600$ per 6-well) were plated on 6-well or 96-wells plates (BD Biosciences, Franklin Lakes, NJ, USA) (day 0). Inhibitors were added on day 1 . On day 6 (96-well) or day 14 (6-well), plates were fixed for 10 min with $96 \%$ methanol, stained with $0.1 \%$ crystal violet and washed with $\mathrm{dH}_{2} \mathrm{O}$. Dried plates were scanned for analysis and analyzed with ImageJ software (NIH, Bethesda, MD, USA). Cell survival graph preparation and IC50 calculation were achieved with GraphPad Prism software (La Jolla, CA, USA).

\section{Time-lapse microscopy}

For live cell imaging, cells were plated in eight-well chamber slides (Ibidi, Martinsried, Germany) in Dulbecco's modified Eagle's medium. Directly before imaging, the medium was replaced by Leibovitz's L-15 (GIBCO, Waltham, MA, USA) $\mathrm{CO}_{2}$-independent medium. Images were obtained using a DeltaVision Elite (Applied Precision, Issaquah, WA, USA) maintained at $37^{\circ} \mathrm{C}$ equipped with a $20 \times 0.75 \mathrm{NA}$ lens (Olympus, Tokyo, Japan) or $40 \mathrm{x}$ 0.6 NA lens (Olympus) and cooled CoolSnap CCD camera (Photometrics, Tucson, AZ, USA). Image analysis was done using ImageJ software (NIH). 
a

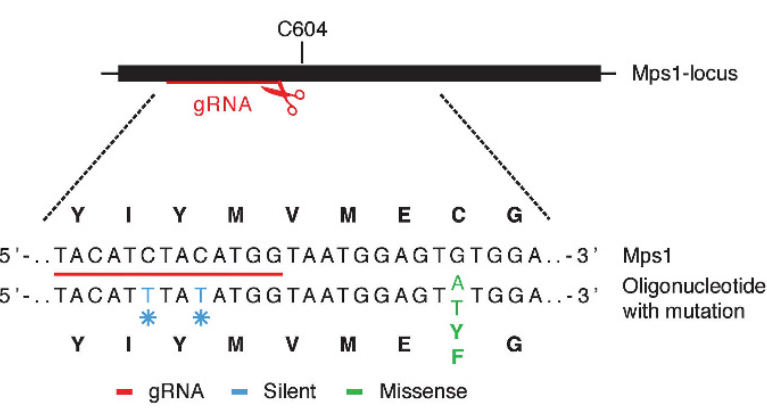

b

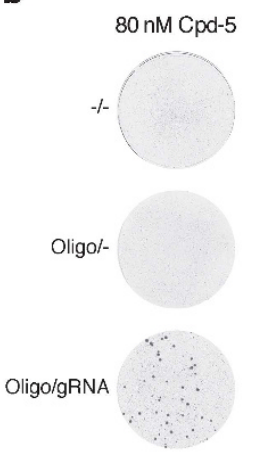

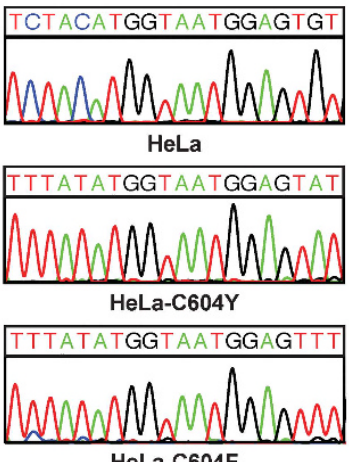

d

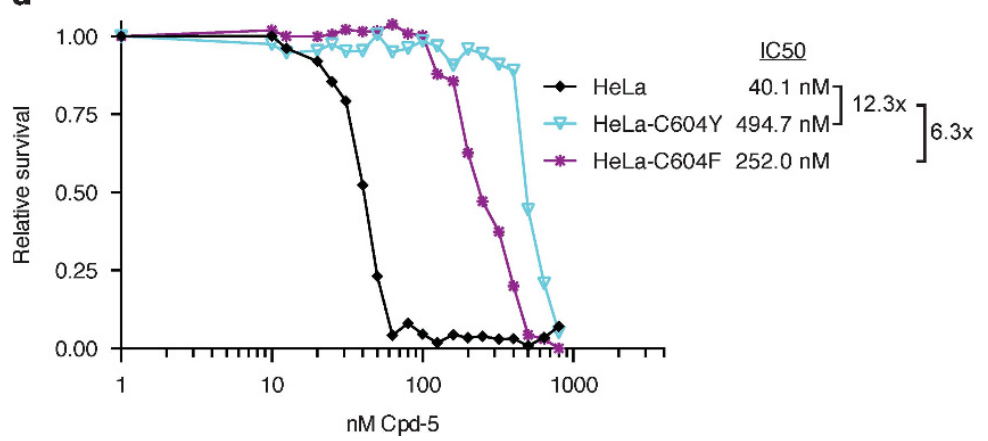

e

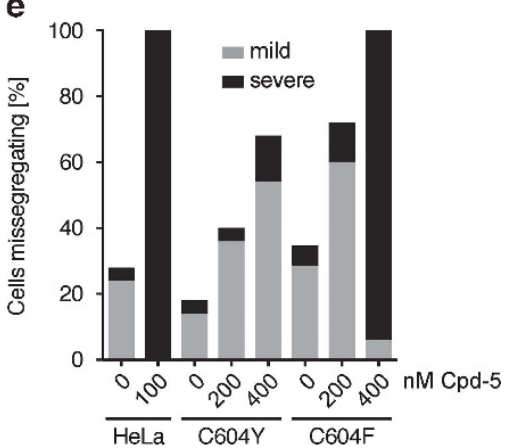

Figure 6. CRISPR/Cas9 genome editing to generate Mps1 mutant cell lines. (a) Schematic of CRISPR/Cas9-mediated genome editing. The oligonucleotide containing two silent and the target mutation serve as a template for homologous recombination dependent repair after Cas9-mediated DNA break formation (b) Crystal violet staining of 10-cm plates after transfection of mock (top), oligonucleotide alone (middle), or oligonucleotide and Cas9/Mps1-targeting gRNA (bottom) followed by selection with $80 \mathrm{~nm}$ Cpd-5 for 14 days. (c) DNA sequence traces of Mps1 cDNA in parental HeLa and clonal selected cells after CRISPR/Cas9-mediated genome editing. (d) Relative survival plots of parental or Mps1-mutated HeLa cells treated for 5 days with increasing concentrations of Cpd-5. Shown is the average of three independent experiments and the calculated $I_{50}$. For better visibility, the s.d. were removed from the graph. (e) Quantification of chromosome missegregations. Two phenotypes are depicted; anaphases with mild missegregations (up to 3 chromosomes) and severe missegregations ( $>3$ chromosomes). Fifty cells per condition were analyzed.

Table 1. IC50s of parental and Mps1 mutant cell lines treated with various Mps1 inhibitors

\begin{tabular}{|c|c|c|c|c|c|c|c|c|c|}
\hline & \multicolumn{3}{|c|}{ HCT-116 } & \multicolumn{2}{|c|}{$D L D-1$} & \multicolumn{4}{|c|}{ Hela } \\
\hline & - & $1531 M$ & C604Y & - & $S 611 R$ & - & $1598 F$ & $\mathrm{C} 604 \mathrm{Y}$ & C604F \\
\hline AZ3146 & 560 & 3063 & $>5000$ & 719 & $>5000$ & 1335 & 3847 & $>5000$ & 2743 \\
\hline Mps1-IN-3 & 1624 & 3234 & 5403 & 2415 & 7931 & 3417 & 4793 & 8974 & 6793 \\
\hline Reversine & 138 & 530 & 70 & 136 & $>2000$ & 290 & 431 & 116 & 125 \\
\hline
\end{tabular}

Shown are the median $\mathrm{IC}_{50} \mathrm{~S}$ (in $\mathrm{nM}$ ) for the Mps1 inhibitors NMS-P715, AZ3146, Mps1-IN-3, MPI-0479605 and reversine. Three independent experiments (Figure 7, Supplementary Figure 10) were the basis of the calculation.

\section{Mitotic index determination}

Cells ( 10000 per well) were plated on 96-wells plates (BD Biosciences) (day 0 ). At day 1 , nocodazole and Cpd-5 were added for $16 \mathrm{~h}$ and cells were fixed using $5 \%$ formaldehyde. Cells were stained with an antibody against phospho-histone H3-Ser10 (Merck Millipore) and 4,6-diamidino-2phenylindole. Image acquisition was performed using a DeltaVision Elite (Applied Precision) using a 10x 0.4NA objective. Up to nine images were acquired per well, which covered around 3000 cells in total. Image analysis was performed using ImageJ software $(\mathrm{NIH})$. The percentage of mitotic cells was determined by the amount of phospho-histone H3-Ser10-positive cells over the total 4,6-diamidino-2-phenylindole-positive cells.

\section{Synthesis of Cpd-5}

Cpd-5 was synthesized as described in patent WO 2009156315 A1 from Nerviano Medical Sciences ${ }^{26}$ (Supplementary Figure 11). Structure 1
$(25 \mathrm{~g}, 225 \mathrm{mmol})$ in toluene $(500 \mathrm{ml})$ and EtOH $(250 \mathrm{ml})$ was added to p-toluenesulfonic acid $(5 \mathrm{~g}, 29 \mathrm{mmol})$. The mixture was refluxed for 4 days. After cooling, the solvent was concentrated and the residue re-dissolved with dichloromethane and washed with a saturated solution of $\mathrm{NaHCO}_{3}$. The organic layer was dried over $\mathrm{NaSO}_{4}$ and concentrated. The crude was purified by flash chromatography to give Structure $\mathbf{2}(18.2 \mathrm{~g}, 58 \%$ yield) as yellow oil.

Structure $2(4.1 \mathrm{~g}, 29.0 \mathrm{mmol})$ in tetrahydrofuran (THF) $(50 \mathrm{ml})$ was added to lithium-bis(trimethylsilyl)amide (LiHMDS) $(32.5 \mathrm{ml} 1 \mathrm{~m} / \mathrm{l}$ in THF) at $-50^{\circ} \mathrm{C}$. After $30 \mathrm{~min}$ at the same temperature, $4.4 \mathrm{ml}$ of diethyl oxalate was also added under stirring. The mixture was stirred at room temperature overnight. The residue was adjusted to $\mathrm{pH} 4-5$ with $1 \mathrm{M} \mathrm{HCl}$, and extracted with ethyl acetate. The combined organic phase was dried, concentrated and purified by flash chromatography to give Structure 3 ( $5.6 \mathrm{~g}, 80 \%$ yield) as yellow oil. 
a

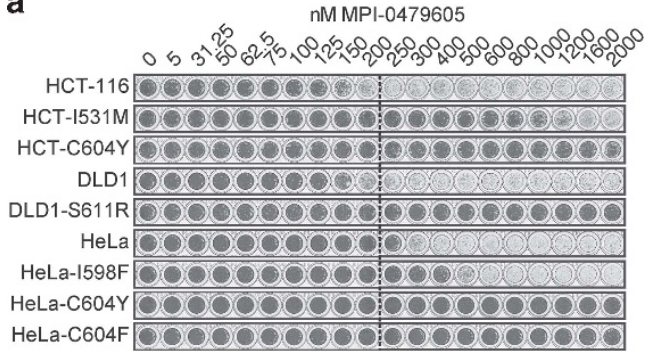

b

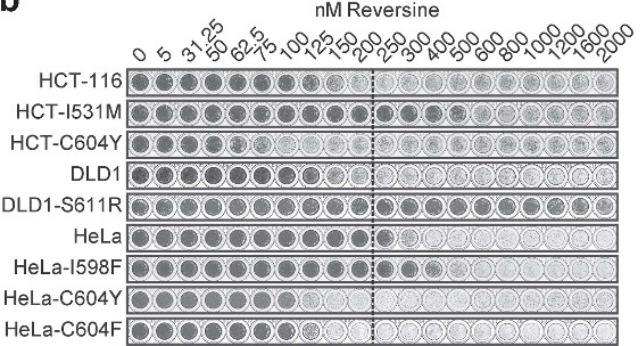

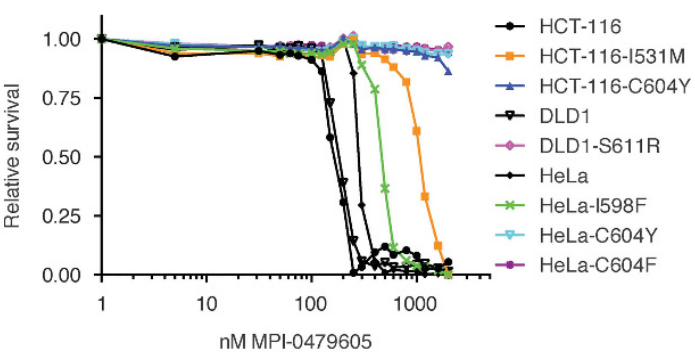

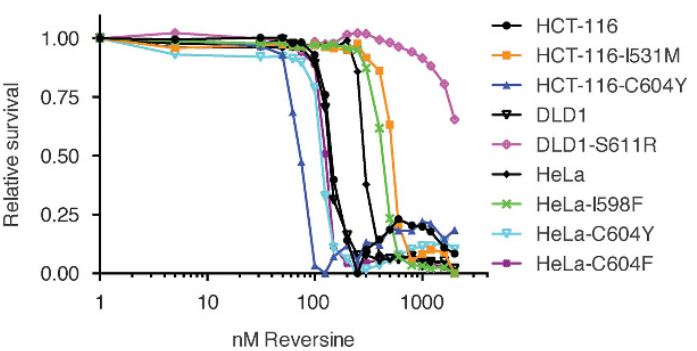

Figure 7. Cross-resistance of the Mps1-mutated cell lines to the Mps1 inhibitors MPI-0479605 and reversine. (a) Left: representative colony formation assays of indicated cell lines treated for 5 days with increasing concentrations of MPI-0479605. Right: relative survival plots showing the average of three independent experiments. (b) Same as in a shown for the Mps 1 inhibitor reversine. For better visibility, the s.d. were removed from the graphs.

Structure $3(5.6 \mathrm{~g}, 23.3 \mathrm{mmol})$ in $\mathrm{AcOH}(30 \mathrm{ml})$ was added to $\mathrm{MeNHNH}_{2}$ $(1.5 \mathrm{ml})$. The mixture was stirred at room temperature for $6 \mathrm{~h}$. The residue was adjusted to $\mathrm{pH} 10-11$ with $30 \% \mathrm{NH}_{4} \mathrm{OH}$, and extracted with $\mathrm{CH}_{2} \mathrm{Cl}_{2}$. The combined organic phase was dried, concentrated and purified by flash chromatography to give Structure $4(4.5 \mathrm{~g}, 87 \%$ yield) as a yellow solid. Structure $4(4.5 \mathrm{~g}, 20.3 \mathrm{mmol})$ in dimethylformamide $(30 \mathrm{ml})$ was added to dimethylformamide diterbutyl acetale $(9 \mathrm{ml})$. The mixture was stirred at $60^{\circ} \mathrm{C}$ for $6 \mathrm{~h}$. The residue was concentrated and the product crystallized form ethanol to give Structure $\mathbf{5}(3.5 \mathrm{~g}, 62.2 \%$ yield) as yellow solid.

To a solution of 4-bromo-2-methoxyaniline $2.0 \mathrm{~g}(10 \mathrm{mmol})$ in $\mathrm{HCl} 25 \%$ $\mathrm{m} / \mathrm{v} 10 \mathrm{ml}$, cyanamide $6.0 \mathrm{~g}(142.8 \mathrm{mmol})$ was added in portion $(0.6 \mathrm{~g}$ every half hour). The reaction was stirred at $60^{\circ} \mathrm{C}$ for $6 \mathrm{~h}$, then cooled down to room temperature, diluted with $\mathrm{H}_{2} \mathrm{O}(10 \mathrm{ml})$, extracted with AcOEt $(10 \mathrm{ml})$. $\mathrm{NaOH} 35 \%(20 \mathrm{ml})$ was added to $\mathrm{pH}$ 14. The aqueous phase was extracted with AcOEt $(3 \times 50 \mathrm{ml})$, dried over $\mathrm{Na}_{2} \mathrm{SO}_{4}$ and concentrated to afford $2.3 \mathrm{~g}$ (quantitative yield) of the title Structure 6 .

Structure $\mathbf{5}(0.8 \mathrm{~g}, 2.9 \mathrm{mmol})$ in dimethylformamide $(10 \mathrm{ml})$ was added to Structure $6(0.9 \mathrm{~g}, 3.7 \mathrm{mmol})$. The mixture was stirred at $120^{\circ} \mathrm{C}$ for $6 \mathrm{~h}$. After cooling down, the product was filtered and washed with $\mathrm{H}_{2} \mathrm{O}$. The solid was dried to give Structure $\mathbf{7}(1.05 \mathrm{~g}, 79 \%$ yield) as yellow solid. To a solution of 2,6-diethylaniline $(480 \mathrm{mg}, 3.3 \mathrm{mmol})$ in THF $10 \mathrm{ml}$, LIHMDS ( $3.3 \mathrm{ml}, 3.3 \mathrm{mmol}$ ) was added drop-wise. The reaction was stirred at $0{ }^{\circ} \mathrm{C}$ for $10 \mathrm{~min}$, then Structure $7(500 \mathrm{mg}, 1.1 \mathrm{mmol})$ in THF $(10 \mathrm{ml}))$ was added drop-wise at $0{ }^{\circ} \mathrm{C}$ and the mixture was stirred at room temperature overnight. Diluted with $\mathrm{H}_{2} \mathrm{O}(10 \mathrm{ml})$. The aqueous phase was extracted with AcOEt $(3 \times 20 \mathrm{ml})$, dried over $\mathrm{Na}_{2} \mathrm{SO}_{4}$ and concentrated to afford crude compound, which was washed with hexane to give Structure 8 (520 mg, $83.9 \%$ yield). $\mathrm{Pd}_{2}(\mathrm{dba})_{3}(4.0 \mathrm{mg})$, Ruphos $(4.0 \mathrm{mg})$ and Structure 8 ( $250 \mathrm{mg}$, $0.45 \mathrm{mmol})$ in THF $(5.0 \mathrm{ml})$ were charged in a round-bottom flask flushed with Ar. LIHMDS ( $3.5 \mathrm{mmol}, 3.5 \mathrm{ml})$ and 1-methylpiperazine $(0.14 \mathrm{ml}, 1.3$ $\mathrm{mmol}$ ) were added and the reaction mixture refluxed for $1 \mathrm{~h}$. The reaction was cooled and concentrated. The crude was purified by flash chromatography to give Structure 9 (= Cpd-5) $(240 \mathrm{mg}, 92 \%$ yield $)$ as a yellow solid.

\section{Compound-5}

${ }^{1} \mathrm{H}$ NMR (400 MHz, DMSO- $\left.d_{6}\right)$ : $\delta$ : p.p.m. $8.26(\mathrm{~s}, 1 \mathrm{H}), 8.14-8.19(\mathrm{~m}, 2 \mathrm{H}), 7.35$ $(\mathrm{s}, 1 \mathrm{H}), 7.25(\mathrm{~s}, 1 \mathrm{H}), 7.15(\mathrm{~m}, 2 \mathrm{H}), 6.58(\mathrm{~m}, 2 \mathrm{H}), 4.41(\mathrm{~s}, 3 \mathrm{H}), 3.90(\mathrm{~s}, 3 \mathrm{H})$, $3.14-3.20(\mathrm{~m}, 6 \mathrm{H}), 2.83-2.87(\mathrm{~m}, 2 \mathrm{H}), 2.60-2.71(\mathrm{~m}, 8 \mathrm{H}), 2.37(\mathrm{~s}, 3 \mathrm{H}), 1.19-1.23$ $(\mathrm{m}, 6 \mathrm{H})$. High-performance liquid chromatography purity: $99.16 \%(254 \mathrm{~nm})$. Mass: $\mathrm{m} / \mathrm{z} 581[\mathrm{M}+1]+$.

\section{Compounds}

Cpd-5, MPI-0479605 (ApexBio, Houston, TX, USA), NMS-P715 (Merck Millipore), reversine (Sigma), Mps1-IN-3 (Sigma) and AZ3146 (Axon Medchem, Groningen, Netherlands) were all dissolved in DMSO.

RNA isolation, CDNA synthesis and sequencing

Total RNA was isolated using the RNeasy Mini Kit (Qiagen) and cDNA was synthesized using SuperScript III First-Strand Synthesis System (Invitrogen) and random hexamer primers according to the manufacturer's instructions.

\section{Western blotting}

Cells were lysed in buffer containing $20 \mathrm{~mm}$ Tris/ $\mathrm{HCl}(\mathrm{pH} 7.5), 150 \mathrm{~mm} \mathrm{NaCl}$, $1 \%$ Triton-X-100, $1 \mathrm{~mm}$ dithiothreitol, $2 \mathrm{~mm}$ EDTA, $1 \mathrm{~mm} \mathrm{NaF}, 1 \mathrm{~mm}$ orthovanadate, $25 \mathrm{~mm}$ beta-glycerophosphate and protease inhibitor cocktail (Roche, Basel, Switzerland). Samples were separated by sodium dodecyl sulfate-polyacrylamide gel electrophoresis and transferred to nitrocellulose membranes, blocked with $4 \%$ bovine serum albumin $(\mathrm{w} / \mathrm{v})$ at room temperature for $0.5 \mathrm{~h}$, and incubated with primary antibodies at $4{ }^{\circ} \mathrm{C}$ overnight. After incubation with secondary antibody (1:2000 dilution) at room temperature for $1 \mathrm{~h}$, the membranes were developed with chemiluminescence ECL reagent (Amersham, Amersham, UK) and pictures were taken with the ChemiDOC XRS+ (Bio-Rad, Hercules, CA, USA).

\section{CRISPR/Cas9-mediated genome editing}

The guide RNA sequence (5'-CACGGACCAGTACATCTACA-3') downstream of Mps1-C604 for the CRISPR/Cas9-mediated genome editing was designed using the CRISPR design web interface provided by the Zhang laboratory (http://crispr.genome-engineering.org/). The guide was cloned into the pX330 vector (obtained from Addgene (Cambridge, MA, USA; 42230)) as described previously. ${ }^{41}$ The generated pX330/gRNA was cotransfected using XtremeGENE9 DNA transfection reagent (Roche) in $1 \times 10^{6}$ HeLa cells together with 100-bp oligonucleotides (C604Y: 5'-GTTTAATTG CAGTGAAATCACGGACCAGTACATTTATATGGTAATGGAGTATGGAAATATTG ATCTTAATAGTTGGCTTAAAAAGAAAAAATCCATTGATC-3'; C604F: 5'-GTTAA ATTGCAGTGAAATCACGGACCAGTACATTTATATGGTAATGGAGTTGGAAATA TTGATCTTAATAGTTGGCTTAAAAAGAAAAAATCCATTGATC-3' synthesized by Integrated DNA Technologies, Inc., Coralville, IA, USA). Two days past transfection, cells were selected with $80 \mathrm{~nm}$ of $\mathrm{Cpd}-5$ for the duration of 
1 week. After single-cell clone isolation, we synthesized cDNA and sequenced Mps1 cDNA.

\section{Protein purification}

GST-KNL1 constructs were generated by insertion of the KNL1-M3 $\left(\right.$ aa801-1052) ${ }^{28}$ into the Xho1 site of pGEX-6P-1. GST-KNL1 constructs were expressed in BL21(DE3):DNAK for $4 \mathrm{~h}$ at $20^{\circ} \mathrm{C}$ with $0.1 \mathrm{~mm}$ isopropyl $\beta$-D-1thiogalactopyranoside. Cell pellets were sonicated and lysed in lysis buffer (1x phosphate-buffered saline solution, $0.1 \%$ Tween, $250 \mathrm{~mm} \mathrm{NaCl}, 1 \mathrm{~mm} 2-$ mercaptoethanol, $1 \mathrm{~mm}$ dithiothreitol and $10 \%$ glycerol). Proteins were purified using glutathioneagarose beads (Sigma) and eluted with $50 \mathrm{~mm}$ Tris- $\mathrm{HCl}$ (pH 8), $10 \mathrm{~mm}$ reduced glutathione (Roche), $75 \mathrm{~mm} \mathrm{KCl}$, followed by buffer exchange using desalting columns (Bio-Rad) in buffer containing $12.5 \mathrm{~mm}$ Tris- $\mathrm{HCl} \mathrm{pH} 7.5,35 \mathrm{~mm} \mathrm{KCl}, 10 \mathrm{~mm} \mathrm{MgCl}, 0.5 \mathrm{~mm}$ EGTA, $0.005 \%$ Triton- $\mathrm{X}$ and $0.1 \mathrm{~mm}$ dithiothreitol.

Mps1 kinase domain constructs (aa519-808) were generated by ligation independent cloning into pETNKI-his3C-LIC-Kan. Mps1 cDNA of hTert-RPE1 cells served as a template. His-Mps1 constructs were expressed in Rosetta (DE3)pLysS for $5 \mathrm{~h}$ at $20^{\circ} \mathrm{C}$ with $0.5 \mathrm{~mm}$ isopropyl $\beta$-D-1-thiogalactopyranoside. Purification was performed as previously described. ${ }^{42}$

\section{In vitro kinase assays}

In all, $100 \mathrm{ng}$ of the different versions of Mps1 was incubated for $10 \mathrm{~min}$ at $32^{\circ} \mathrm{C}$ with the indicated compounds in a buffer containing $50 \mathrm{~mm}$ Tris- $\mathrm{HCl}$ $\mathrm{pH} 7.5,100 \mathrm{~mm} \mathrm{NaCl}, 20 \mathrm{~mm} \mathrm{MgCl}, 1 \mathrm{~mm}$ dithiothreitol and $0.2 \mathrm{~mm}$ ATP. After this incubation, $200 \mathrm{ng}$ of purified GST-KNL1-M3 was added, and the mixture was incubated for $60 \mathrm{~min}$ at $32{ }^{\circ} \mathrm{C}$ before addition of SDS-sample buffer and boiling at $95^{\circ} \mathrm{C}$ for $10 \mathrm{~min}$.

\section{Modeling}

Amino-acid mutations were modeled in the structure of the Mps1 kinase domain complexed with NMS-P715 ${ }^{12}$ (PDB identifier 2X9E), using the program Coot. ${ }^{43}$ For all amino-acid side chains, a conformer was chosen that belongs to the top 3 most frequently occurring conformers, and which fitted best in the Mps1 protein structure. Unless otherwise indicated, no adjustments or energy minimizations were performed on non-mutated parts of Mps1. Pictures were made using the program Pymol (New York, NY, USA).

\section{CONFLICT OF INTEREST}

The authors declare no conflict of interest.

\section{ACKNOWLEDGEMENTS}

We thank Geert Kops (UMC Utrecht, The Netherlands) Susanne Lens (UMC Utrecht, The Netherlands) and Anastassis Perrakis (NKI, Amsterdam, The Netherlands) for reagents. Roos Klop, Yoshitaka Hiruma and Mathijs Vleugel for technical help. Bram van den Broek (NKI, Amsterdam, The Netherlands) for providing the ImageJ analysis macro for mitotic index analysis. We thank our colleagues for support and helpful suggestions. The research was funded by the NWO Gravitation Program (Cancer Genomics Center, CGC.nl). AK was supported by an EMBO long-term fellowship (ALTF-425-2013).

\section{AUTHOR CONTRIBUTIONS}

AK performed experimental research and analysis, supervised by RHM. AM performed genome editing for the HeLa-C604F cell line and experimental characterization of the HeLa-C604Y and C604F cell line. AJ was involved in the initial characterization of Cpd-5. AK and RHM wrote the manuscript.

\section{REFERENCES}

1 Abrieu A, Magnaghi-Jaulin L, Kahana JA, Peter M, Castro A, Vigneron S et al. Mps 1 is a kinetochore-associated kinase essential for the vertebrate mitotic checkpoint. Cell 2001; 106: 83-93.

2 Hardwick KG, Weiss E, Luca FC, Winey M, Murray AW. Activation of the budding yeast spindle assembly checkpoint without mitotic spindle disruption. Science 1996; 273: 953-956.
3 Stucke VM, Sillje HH, Arnaud L, Nigg EA. Human Mps1 kinase is required for the spindle assembly checkpoint but not for centrosome duplication. EMBO J 2002; 21: $1723-1732$.

4 Musacchio A, Salmon ED. The spindle-assembly checkpoint in space and time. Nat Rev Mol Cell Biol 2007; 8: 379-393.

5 London N, Ceto S, Ranish JA, Biggins S. Phosphoregulation of Spc105 by Mps1 and PP1 regulates Bub1 localization to kinetochores. Curr Biol 2012; 22: 900-906.

6 Shepperd LA, Meadows JC, Sochaj AM, Lancaster TC, Zou J, Buttrick GJ et al. Phosphodependent recruitment of Bub1 and Bub3 to Spc7/KNL1 by Mph1 kinase maintains the spindle checkpoint. Curr Biol 2012; 22: 891-899.

7 Yamagishi Y, Yang $\mathrm{CH}$, Tanno Y, Watanabe Y. MPS1/Mph1 phosphorylates the kinetochore protein KNL1/Spc7 to recruit SAC components. Nat Cell Biol 2012; 14: 746-752.

8 Janssen A, Kops GJ, Medema RH. Elevating the frequency of chromosome missegregation as a strategy to kill tumor cells. Proc Natl Acad Sci USA 2009; 106: 19108-19113.

9 Daniel J, Coulter J, Woo JH, Wilsbach K, Gabrielson E. High levels of the Mps1 checkpoint protein are protective of aneuploidy in breast cancer cells. Proc Natl Acad Sci USA 2011; 108: 5384-5389.

10 Lan W, Cleveland DW. A chemical tool box defines mitotic and interphase roles for Mps1 kinase. J Cell Biol 2010; 190: 21-24.

11 Liu X, Winey M. The MPS1 family of protein kinases. Annu Rev Biochem 2012; 81: 561-585.

12 Colombo R, Caldarelli M, Mennecozzi M, Giorgini ML, Sola F, Cappella P et al. Targeting the mitotic checkpoint for cancer therapy with NMS-P715, an inhibitor of MPS1 kinase. Cancer Res 2010; 70: 10255-10264.

13 Jemaa M, Galluzzi L, Kepp O, Senovilla L, Brands M, Boemer U et al. Characterization of novel MPS1 inhibitors with preclinical anticancer activity. Cell Death Differ 2013; 20: 1532-1545.

14 Tannous BA, Kerami M, Van der Stoop PM, Kwiatkowski N, Wang J, Zhou W et al. Effects of the selective MPS1 inhibitor MPS1-IN-3 on glioblastoma sensitivity to antimitotic drugs. J Natl Cancer Inst 2013; 105: 1322-1331.

15 Tardif KD, Rogers A, Cassiano J, Roth BL, Cimbora DM, McKinnon R et al. Characterization of the cellular and antitumor effects of MPI-0479605, a smallmolecule inhibitor of the mitotic kinase Mps1. Mol Cancer Ther 2011; 10: 2267-2275.

16 Hewitt L, Tighe A, Santaguida S, White AM, Jones CD, Musacchio A et al. Sustained Mps1 activity is required in mitosis to recruit O-Mad2 to the Mad1-C-Mad2 core complex. J Cell Biol 2010; 190: 25-34.

17 Santaguida S, Tighe A, D'Alise AM, Taylor SS, Musacchio A. Dissecting the role of MPS1 in chromosome biorientation and the spindle checkpoint through the small molecule inhibitor reversine. J Cell Biol 2010; 190: 73-87.

18 Barouch-Bentov R, Sauer K. Mechanisms of drug resistance in kinases. Expert Opin Investig Drugs 2011; 20: 153-208.

19 Liu Y, Gray NS. Rational design of inhibitors that bind to inactive kinase conformations. Nat Chem Biol 2006; 2: 358-364.

20 Chong CR, Janne PA. The quest to overcome resistance to EGFR-targeted therapies in cancer. Nat Med 2013; 19: 1389-1400.

21 Gorre ME, Mohammed M, Ellwood K, Hsu N, Paquette R, Rao PN et al. Clinical resistance to STI-571 cancer therapy caused by BCR-ABL gene mutation or amplification. Science 2001; 293: 876-880.

22 Weisberg E, Manley PW, Cowan-Jacob SW, Hochhaus A, Griffin JD. Second generation inhibitors of $B C R-A B L$ for the treatment of imatinib-resistant chronic myeloid leukaemia. Nat Rev Cancer 2007; 7: 345-356.

23 Girdler F, Sessa F, Patercoli S, Villa F, Musacchio A, Taylor S. Molecular basis of drug resistance in aurora kinases. Chem Biol 2008; 15: 552-562.

24 Wacker SA, Houghtaling BR, Elemento O, Kapoor TM. Using transcriptome sequencing to identify mechanisms of drug action and resistance. Nat Chem Biol 2012; 8: 235-237.

25 Scutt PJ, Chu ML, Sloane DA, Cherry M, Bignell CR, Williams DH et al. Discovery and exploitation of inhibitor-resistant aurora and polo kinase mutants for the analysis of mitotic networks. J Biol Chem 2009; 284: 15880-15893.

26 Marina Caldarelli MA, Colombo R, Disingrini T, Nuvoloni S, Posteri H, Salsa M et al. Pyrazolo-quinazolines 2009; WO 2009156315 A1.

27 Glaab WE, Tindall KR. Mutation rate at the hprt locus in human cancer cell lines with specific mismatch repair-gene defects. Carcinogenesis 1997; 18: 1-8.

28 Vleugel M, Tromer E, Omerzu M, Groenewold V, Nijenhuis W, Snel B et al. Arrayed BUB recruitment modules in the kinetochore scaffold KNL1 promote accurate chromosome segregation. J Cell Biol 2013; 203: 943-955.

29 Kornev AP, Taylor SS, Ten Eyck LF. A helix scaffold for the assembly of active protein kinases. Proc Natl Acad Sci USA 2008; 105: 14377-14382.

30 Chu ML, Lang Z, Chavas LM, Neres J, Fedorova OS, Tabernero L et al. Biophysical and X-ray crystallographic analysis of Mps1 kinase inhibitor complexes. Biochemistry 2010; 49: 1689-1701.

31 Schmidt M, Budirahardja Y, Klompmaker R, Medema RH. Ablation of the spindle assembly checkpoint by a compound targeting Mps1. EMBO Rep 2005; 6: 866-872. 
32 Cho SW, Kim S, Kim JM, Kim JS. Targeted genome engineering in human cells with the Cas9 RNA-guided endonuclease. Nat Biotechnol 2013; 31: 230-232.

33 Mali $\mathrm{P}$, Yang L, Esvelt KM, Aach J, Guell M, DiCarlo JE et al. RNA-guided human genome engineering via Cas9. Science 2013; 339: 823-826.

34 Forbes SA, Beare D, Gunasekaran P, Leung K, Bindal N, Boutselakis H et al. COSMIC: exploring the world's knowledge of somatic mutations in human cancer. Nucleic Acids Res 2015; 43: D805-D811.

35 Eyers PA, Churchill ME, Maller JL. The Aurora A and Aurora B protein kinases: a single amino acid difference controls intrinsic activity and activation by TPX2. Cell Cycle 2005; 4: 784-789.

36 Sloane DA, Trikic MZ, Chu ML, Lamers MB, Mason CS, Mueller I et al. Drug-resistant aurora A mutants for cellular target validation of the small molecule kinase inhibitors MLN8054 and MLN8237. ACS Chem Biol 2010; 5: 563-576.

37 D'Alise AM, Amabile G, lovino M, Di Giorgio FP, Bartiromo M, Sessa F et al. Reversine, a novel Aurora kinases inhibitor, inhibits colony formation of human acute myeloid leukemia cells. Mol Cancer Ther 2008; 7: 1140-1149.

38 Vijay Kumar D, Hoarau C, Bursavich M, Slattum P, Gerrish D, Yager K et al. Lead optimization of purine based orally bioavailable Mps1 (TTK) inhibitors. Bioorg Med Chem Lett 2012; 22: 4377-4385.

39 Naud S, Westwood IM, Faisal A, Sheldrake P, Bavetsias V, Atrash B et al. Structure-based design of orally bioavailable $1 \mathrm{H}$-pyrrolo[3,2-c]pyridine inhibitors of mitotic kinase monopolar spindle 1 (MPS1). J Med Chem 2013; 56: 10045-10065.

40 Nijenhuis W, Vallardi G, Teixeira A, Kops GJ, Saurin AT. Negative feedback at kinetochores underlies a responsive spindle checkpoint signal. Nat Cell Biol 2014; 16: 1257-1264.

41 Cong L, Ran FA, Cox D, Lin S, Barretto R, Habib N et al. Multiplex genome engineering using CRISPR/Cas systems. Science 2013; 339: 819-823.

42 Kwiatkowski N, Jelluma N, Filippakopoulos P, Soundararajan M, Manak MS, Kwon M et al. Small-molecule kinase inhibitors provide insight into Mps1 cell cycle function. Nat Chem Biol 2010; 6: 359-368.

43 Emsley P, Lohkamp B, Scott WG, Cowtan K. Features and development of coot. Acta Crystallogr D Biol Crystallogr 2010; 66: 486-501.

(c) (1) This work is licensed under a Creative Commons Attributioncc. No NG SA Nommercial-ShareAlike 4.0 International License. The images or other third party material in this article are included in the article's Creative Commons license, unless indicated otherwise in the credit line; if the material is not included under the Creative Commons license, users will need to obtain permission from the license holder to reproduce the material. To view a copy of this license, visit http:// creativecommons.org/licenses/by-nc-sa/4.0/

Supplementary Information accompanies this paper on the Oncogene website (http://www.nature.com/onc) 